\title{
Clinical trials: two neglected ethical issues
}

\author{
Andrew Herxheimer UK Cochrane Centre, University of Oxford
}

\section{Author's abstract}

Ethical reasons are presented for requiring 1) that a proposal for a clinical trial should be accompanied by a thorough review of all previous trials that have examined the same and closely related questions, and 2) that a trial should be approved by a research ethics committee only if the investigator undertakes to register it in an appropriate register of clinical trials as soon as one exists.

\section{Introduction}

Important questions to be asked about a clinical trial include: 1) Why is the trial necessary, or worth doing? 2) Will the findings of the trial be made public? Both questions raise ethical issues, discussed below, which have implications for the work of ethics committees.

\section{1) The need for systematic review}

A trial may be necessary to answer an important unanswered question. It may be that the question has been examined in previous trials, with inconclusive or conflicting results; or it may not have been addressed before. However, if the question has been clearly answered by previous trials, the gain from doing another may be negligible, and it would not be justified. A well known example is the use of a placebo in a condition for which a treatment of proven effectiveness exists. In such a case the use of a placebo is unacceptable, unless the condition is a trivial one.

It follows that a proposal for a trial should be accompanied by a thorough review of all previous trials that have examined the same and closely related questions. Only in the light of such a review can a sound opinion be given on whether the proposal is ethical.

\section{Key words}

Clinical trials; systematic review of clinical trials; publication of clinical trials; registration of clinical trials.

\section{2) Publication of the results}

It is important that the evidence generated in well performed clinical trials is published, but much of it remains inaccessible. This under-reporting of $i$ research must be regarded as a form of scientific $\vec{I}$ misconduct, because it creates a distortion in the $\frac{0}{2}$ publicly available evidence. It represents not only a $\rightarrow$ waste of the resources used in the unreported work (patients' co-operation, investigators' skill, health facilities, time, money), but impedes the use of effec- 3 tive treatment or the abandonment of ineffective $\mathbb{\Phi}$ treatment; it also requires otherwise avoidable sub- $\vec{\theta}$ sequent research to correct the distortions. It \&s $\&$ mainly investigators and commercial sponso rather than referees or journal editors, who appear be responsible for the under-reporting (1 Investigators, research ethics committees and $\overline{0}$ funding agencies should all take steps to ensure that this form of scientific misconduct is minimised.

It may be unrealistic to expect all trials to be pub- $\overrightarrow{\hat{O}}$ lished, but their findings must be made accessible to 3 anyone wishing to make a systematic review of the trials concerned with a particular problem. The first? step towards this goal is to ensure that it is possible to obtain a complete listing of these trials, and the names and addresses of the people who have information $\frac{5}{3}$ about them. A simple way of achieving this would be to register all clinical trials at inception in a registerô (2). Such registers already exist for trials in some areas of medicine. However, more systematic development $\mathrm{O}$ of such registers is needed, both in Britain and in other countries. Ethics committees have important opportunities to foster these developments and to ensure ${ }_{0}$ that the necessary information is assembled efficiently.

\section{Implications for ethics committees}

Ethics committees should routinely require that $x$ proposal to undertake a clinical trial be accompanied $\Phi$ by a systematic review of previous work concerned ${ }^{+}$ with the same and closely related questions, so that ${ }_{0}^{\circ}$ the proposal can be put into its proper context.

Approval by an ethics committee of a proposal to $\stackrel{\mathbb{Q}}{\mathbb{P}}$ do a trial should be conditional on it being registered $\varrho$

continued on page 218 
(3) Bartlett R H et al. Extracorporeal membrane oxygenation (ECMO) cardiopulmonary support in infancy. Transactions of the American Society for Artificial Internal Organs 1976 Apr, 22: 80-93.

(4) Neonatal ECMO registry of the extracorporeal Life Support Organization (ELSO). Ann Arbor, MI: 1992 Jul.

(5) Stolar C J H, Snedecor S M, Bartlett R H. Extracorporeal membrane oxygenation and neonatal respiratory failure: experience of the Extracorporeal Life Support Organization. Fournal of pediatric surgery 1991; 26: 563-571.

(6) Bartlett $\mathrm{R} \mathrm{H}$ et al. Extracorporeal circulation in neonatal respiratory failure: a prospective randomized study. Pediatrics 1985; 76: 479-487.

(7) Wei L J, Durham S D. The randomized playthe-winner rule in medical trials. Fournal of the American Statistical Association 1978; 73: 830-843.

(8) O'Rourke P P et al. Extracorporeal membrane oxygenation and conventional medical therapy in neonates with persistent pulmonary hypertension of the newborn: a prospective randomized study. Pediatrics 1989; 84: 957-963.

(9) Knox R A. A Harvard study on newborns draws fire: doctors faulted for limiting life-saving treatment. Boston globe 1989 Aug 7.

(10) Wung J T et al. Management of infants with severe respiratory failure and persistence of the fetal circulation, without hyperventilation. Pediatrics 1985; 76: 488-494.

(11) Dworetz A R et al. Survival of infants with persistent pulmonary hypertension without extracorporeal membrane oxygenation. Pediatrics 1989; 84: 1-6.

(12) Advertisement. America West Airlines magazine 1990; 5, 3: 6 .

(13) Ware J H. Investigating therapies of potentially great benefit: ECMO [with discussion]. Statistical science 1989; 4: 298-340.

(14) Berwick D M, Fineberg H V, Weinstein M C. When doctors meet numbers. American journal of medicine 1981; 71: 991-998.
(15) Miké V. Philosophers assess randomized clinical trials: the need for dialogue. Controlled clinical trials 1989; 10: 244-253.

(16) Zelen M. A new design for randomized clinical trials. New England journal of medicine 1979; 300: 1242-1245.

(17) Freedman B. Equipoise and the ethics of clinical research. New England journal of medicine 1987; 317: 141-145.

(18) Lantos J D, Frader J. Extracorporeal membrane oxygenation and the ethics of clinical research in pediatrics. New England journal of medicine 1990; 323: 409-413.

(19) Miké V. Clinical studies in cancer: a historical perspective. In: Miké V, Stanley K E, eds. Statistics in medical research: methods and issues, with applications in cancer research. New York: John Wiley \& Sons, 1982: 111-155.

(20) Miké V. Understanding uncertainties in medical evidence: professional and public responsibilities. In: Mayo D G, Hollander R D, eds. Acceptable evidence: science and values in risk management. New York: Oxford University Press, 1991: 115-136.

(21) Relman A S. Assessment and accountability: the third revolution in medical care. New England journal of medicine 1988; 319: 1220-1222.

(22) Ellwood P M. Outcomes management: a technology of patient experience. New England journal of medicine 1988; 318: 1549-1556.

(23) Pellegrino E D. The metamorphosis of medical ethics: a 30-year retrospective. Fournal of the American Medical Association 1993; 269: 11561162.

(24) Katz J. Randomized clinical trials: 'Am I my brother's ? keeper?' Fournal of clinical gastroenteroiogy 1981; 3 (suppl 2): 141-146.

(25) Lebacqz K. Imperiled in the wilderness. Second opinion 1986; 2: 26-31.

(26) Silverman W A. Epoché in retinopathy of prematurity. Archives of disease in childhood 1986; 61: $522-525$. in an appropriate register of clinical trials as soon as one exists.

Andrew Herxheimer, FRCP, is a Consultant at the UK Cochrane Centre, Oxford, part of the international Cochrane collaboration, which prepares and maintains systematic, up-to-date reviews of randomized controlled trials of health care. UK Cochrane Centre, University of Oxford, NHS Research and Development Programme,
Summertown Pavilion, Middle Way, Oxford, OX2 $7 L G$.

\section{References}

(1) Chalmers I. Under-reporting research is scientific misconduct. Fournal of the American Medical Association 1990; 263: 1405-1408.

(2) Anonymous. Making clinical trialists register. Lancet 1991; 338: 244. 